Virginia Commonwealth University

VCU Scholars Compass

1989

\title{
Optical and electrochemical studies of passive film formation in amorphous Ni-Cr-P-C alloys
}

D. B. Hagan

Virginia Commonwealth University

B. W. Sloope

Virginia Commonwealth University

V.A. Niculescu

Virginia Commonwealth University

Follow this and additional works at: http://scholarscompass.vcu.edu/phys_pubs

Part of the Physics Commons

Hagan, D. B., Sloope, B. W., Niculescu, V. A. Optical and electrochemical studies of passive film formation in amorphous Ni-Cr-P-C alloys. Journal of Applied Physics 66, 3942 (1989). Copyright C) 1989 AIP Publishing LLC.

\section{Downloaded from}

http://scholarscompass.vcu.edu/phys_pubs/136

This Article is brought to you for free and open access by the Dept. of Physics at VCU Scholars Compass. It has been accepted for inclusion in Physics Publications by an authorized administrator of VCU Scholars Compass. For more information, please contact libcompass@vcu.edu. 
to be caused by formation of an amorphous layer at grain boundaries. Thermal annealing after ion irradiation causes irreversible compositional changes near the film sutace. ${ }^{14,15}$ We do not observe such severe segregation in our films even though our doses and annealing temperatures are relatively high. White et al. ${ }^{16}$ found that the damage due to the films is greater wher they are implanted below $90 \mathrm{~K}$. Our films may have escaped this level of damage because they were implanted at room temperature.

The above results show that a $\mathrm{Y}-\mathrm{Ba}-\mathrm{Cu}-\mathrm{O} \mathrm{Nm}$ can be compensated for a Cu deficiency by ion implantation with a signiflcant improvement in zero-resistance temperature. Better results may result with closer approach to the stoichoimetric composition.

This work was supported by the Assistant Secretary for Conservation and Renewable Energy, Office of Energy Storage and Distribution, Energy Storage Division, of the U.S. Department of Energy under Contract No. DE-ACO3. 76SF00098. The authors wish to thank Professor A. Zettl for the use of resistance measurement apparatus, and Dr. K. M. Yu for performing the RBS analysis.

'G. J. Clark, A. D. Marwick, R. H. Koch, and R. B. Laibowitz, Appl. Phys. Lett. 51, $139(1987)$

'G. J. Clark, F. K. LeGoles, A. D. Marwick, R. B. Laibowitz, and R.
Koch, Appl. Phys. Lett. 51, 1462 (1987).

${ }^{3}$ R. H. Koch, C. P. Umbach, G. J. Clark, P. Chaudari, and R. B. Laibowitz, Appl. Phys. Lett. 51, 200 (1987).

${ }^{4}$ M. Nastasi, J. R. Tesmer, M. G. Hollander, J. F. Smith, and C. J. Magiore, Appl. Phys. Lett. 52, 1729 (1988).

${ }^{5}$ K. Char, A. D. Kent, A. Kapitulnik, M. R. Beasley, and T. H. Geballe, Appl. Phys. Lett. 51, 1370 (1987)

${ }^{6}$ R. M. Silver, J. Talvacchio, and A. L. de Lozanne, Appl. Phys. Lett. 51 . $2149(1987)$

7T. Aida, T. Fukazawa, K. Takagi, and K. Miyauchi, Jpn. J. Appl. Phys. 26, L 1489 (1987).

${ }^{*}$ N. Terada, H. Thara, M. Jo, M. Hirabayashi, Y. Kimura, K. Matsutani, K. Hirata, E. Ohno, R. Sugise, and F. Kawashima, Jpn. J. Appl. Phys. 27, L639 (1988).

"R. L. Sandstrom, W. L. Gallagher, T. R. Dinger, R. H. Koch, R. B. Laibowitz, A. W. Kleinsasser, R. J. Gambinn, B. Bumble, and M. F. Chisholm, Appl. Phys. Eett. 53, 444 (1988).

${ }^{10}$ S. H. Liou, M. Mong, J. Kwo, B. A. Davidson, H. S. Chen, S. Nakahara, T. Boone, and R. J. Felder, Appl. Phys. Lett. 52, 1735 (1988).

"i. G. Brown, J. E. Galvin, and R. A. MacGill, Appl. Phys. Lett. 47, 358 (1985).

12. G. Brown, J. E. Galvin, and B. Feinberg, J. Appl. Phys. 63, 4889 (1988).

${ }^{13}$ J. Biersack and W. G. Eckstein, Appl. Whys. A 34, 73 (1984)

${ }^{14}$ J. C. McCallum, C. W. White, and L. A. Boatner, Mater. Lett. 6, 374 (1988).

15N. G. Stoeffel, W. A. Bonner, P. A. Morris, and B. J. Wilkens, Mater. Res. Soc. Symp. Proc. 99, 507 (1988).

${ }^{i f}$ A. E. White, K. T. Short, D. C. Jacobson, J. M. Poate, R. C. Dynes, P. M. Mankiewich, W. J. Skocpol, R. E. Howard, M. Anzlowar, K. W. Baldwin, A. F. J. Levi, J. R. Kwo, 'T. Hsieh, and M. Hong, Phys. Rev. B 37, $3755(1988)$

\title{
Optical and electrochemical studies of passive film formation in amorphous Ni-Cr-P.C alloys
}

\author{
D. B. Hagan, B. W. Sloope, and V. A. Niculescu \\ Physics Department, Virginia Commonwealth University, Richmond, Virginia 23284
}

(Received 25 February 1988; accepted for publication 15 May 1989)

\begin{abstract}
The investigation of passivation of an amorphous $\mathrm{Ni}-14 \mathrm{Cr}-17 \mathrm{P}-0.5 \mathrm{C}$ alloy in $1 \mathrm{~N} \mathrm{H}_{2} \mathrm{SO}_{4}$ through anodic polarization and near-normal optical reflectance is reported. It was found that the alloy passivates with a current density of $10^{-1} \mathrm{~A} / \mathrm{m}^{2}$ extending to $1.0 \mathrm{~V}$ with current density dependent upon surface morphology. In the transpassive region under constant current density conditions the reflectance of the film exhibits strong interference phenomena and overall exponential decay in intensity. The behavior of the system in this region is described with a single thin-film optical model consistent with the formation of a chromium phosphate deposit layer which increases in thickness at a rate of $7 \mathrm{~mm} / \mathrm{s}$ at a $1.67 \mathrm{mV} / \mathrm{s}$ sweep rate.
\end{abstract}

Amorphous nickel based alloys have been of interest for their mechanical, magnetic, and corrosion properties. ${ }^{1.5}$ In particular, they display enhanced corrosion resistance and passivity relative to crystalline alloys of the same composition and passivity enhancement as a function of increased concentration of certain metals, notably $\mathrm{Cr}$ and $\mathrm{Mo}$. In the $\mathrm{Ni}$-Cr-type alloys the corrosion enhancernent is due to the formation of a passivating chromium oxyhydroxide ellm. ${ }^{6.7}$

In this communication we performed simultaneous po- tentiodynamic polarization and monochromatic reflectance measurements on an amorphous $\mathrm{Ni}-14 \mathrm{Cr}-17 \mathrm{P}-0.5 \mathrm{C}$ alloy in order to obtain real time information on passive film formation and surface morphology of this system.

The samples used (Mfr. Id. No. MBF65, provided by Allied Corporation Metglas Products Division ${ }^{8}$ ) have a nominal composition Ni-14Cr-17P-0.5C. They are produced in ribbons, $5.0 \mathrm{~cm}$ wide and $35 \mu \mathrm{m}$ thick, and cut for use in circular form with a $0.79 \mathrm{~cm}^{2}$ exposed area. The sam- 


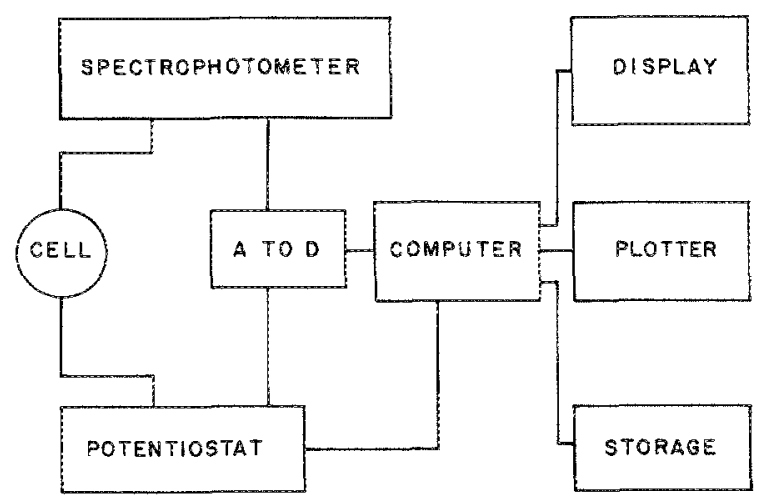

FIG. 1. The block diagram of the instrument.

ples, as supplied, had one shiny side and the other side somewhat duller in appearance. The foils were analyzed by $\$$-ray diffraction and found to be uniformly amorphous. This study was carried out with a computer-controlled instrument which allows simultaneous in situ measurements of near-normal monochromatic reflectance for wavelengths from 300 to $800 \mathrm{~mm}$ and several electrochemical processes. A block diagram of the instrument is shown in Fig.1. Electrochemical measurements have been carried out with a threeelectrode potentiostat and cell which is an expansion of the instrument which has been reported" with enhanced computer capabilities. A standard $\mathrm{Ag} / \mathrm{AgCl}$ reference electrode was used. The potentiodynamic polarization was performed at a sweep rate of $1.67 \mathrm{mV} / \mathrm{s}$ through the corrosion potential up to $3.8 \mathrm{~V}$ in $1 \mathrm{~N} \mathrm{H}_{2} \mathrm{SO}_{4}$. The current limit imposed on the system is $13.65 \mathrm{~mA}$ or a current density of $171 \mathrm{~A} / \mathrm{m}^{2}$ with the $0.79 \mathrm{~cm}^{2}$ sample area. The optical refiectance was measured through a bifurcated fiber optics tube fitted in the electrochemical cell in a manner suggested by Puyn and Park ${ }^{10}$ and by Reed and Hawkridge. ${ }^{\text {" }}$

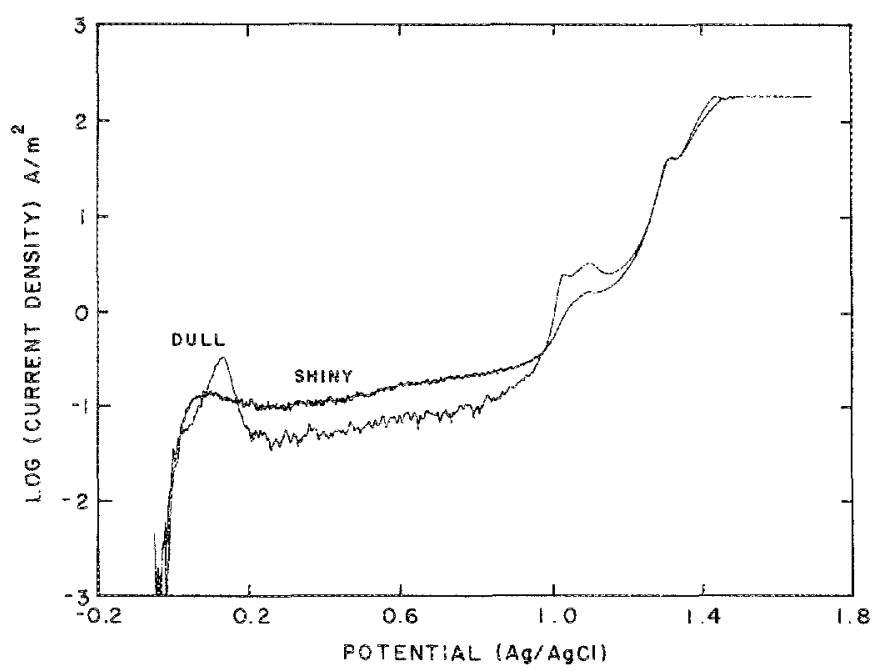

FIG. 2. Potentiodynamic polarization of the dull and shiny sides of MBH65 in $1 \mathrm{~N} \mathrm{H}_{2} \mathrm{SO}_{4}$ at a sweep rate of $1.67 \mathrm{mV} / \mathrm{s}$.

Polarization current density and refiectance as a function of potential were measured for dull, shiny, and polished samples of both surfaces for multiple samples of the MBF65 with very good repeatability. Surface structure and morphology were investigated by scanning electron microscopy (SEM) and energy dispersive $x$-ray dot mapping. X-ray photoemission spectroscopy (XPS) spectra from the surface of treated samples was performed with a Physical Electronics 5100 ESCA system with MgKa excitation. Film thickness was measured on polished samples with a Reichert polarizing interferometer in 590-nm light. An Abbe refractometer was used to determine the index of refraction of the electrolyte at a temperature of $20^{\circ} \mathrm{C}$.

SEM studies of the sample surfaces showed convolutions on the dull side while the shiny side was smooth and

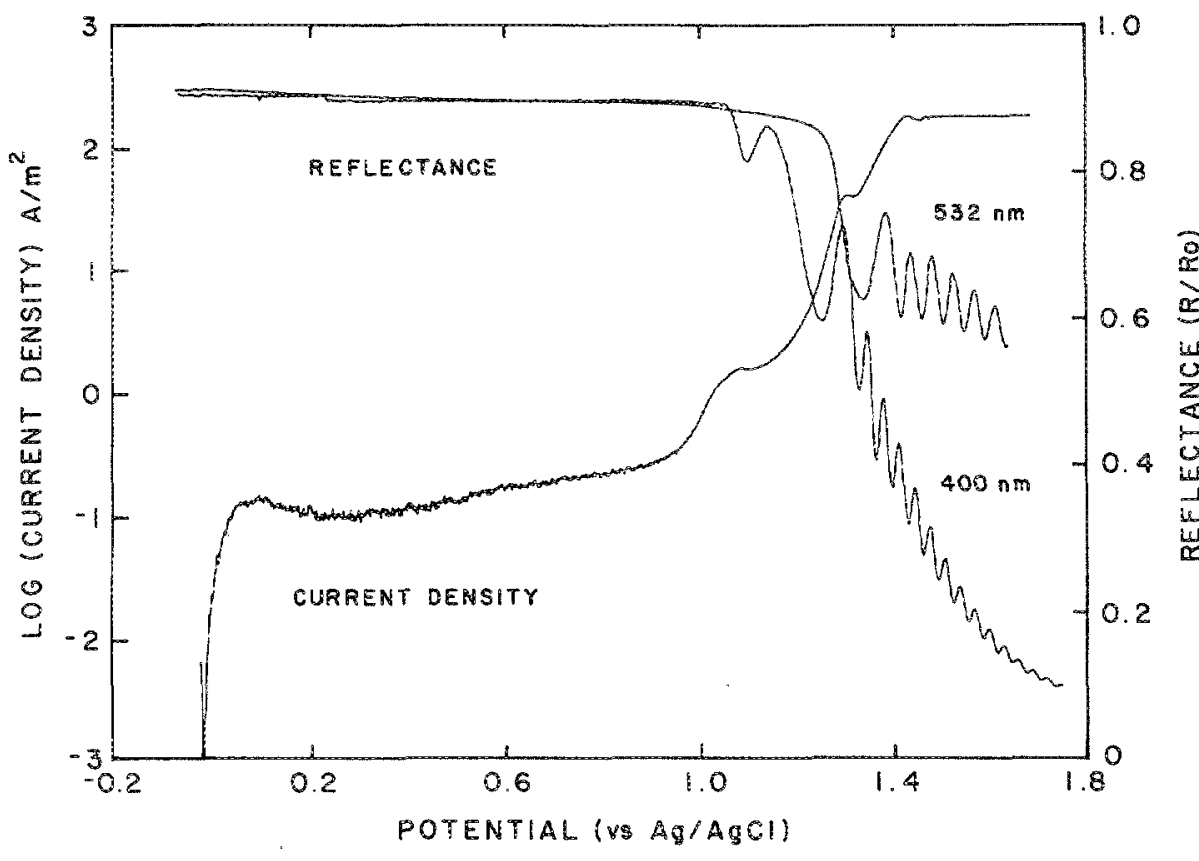

FIG. 3. Potertiodynamic polarization of MBF 65 in $1 \mathrm{NH}_{2} \mathrm{SO}_{4}$ at a sweep rate of $1.67 \mathrm{maV} / \mathrm{s}$ with normalized reflectance. 
TABLE I. Single thin-film model optical parameters used in Eq. (1)

\begin{tabular}{lllll}
\hline & nm & $n$ & $k$ & $\beta$ \\
\hline Elecirolyte & 400 & $1.36^{\prime \prime}$ & $0.01^{\mathrm{b}}$ & $0.25^{\circ}$ \\
& 532 & $1.36^{\mathrm{a}}$ & $0.01^{\mathrm{b}}$ & $0.05^{\circ}$ \\
& & & & \\
Finm & & & & \\
& 400 & 1.58 & 0.019 & \\
& 532 & 1.58 & 0.019 & \\
Metal alloy $^{*}$ & 400 & 1.81 & 3.12 & \\
& 532 & 1.81 & 3.12 & \\
\hline \hline
\end{tabular}

Values obtained from the following:

Refractometry of fuid at $1.7 \mathrm{~V}$

b Fit to curve.

Absorption spectroscopy $0.245 \mathrm{~mm}^{-1}$ at $400,0.055 \mathrm{~mm}^{-1}$ at $532 \mathrm{~nm}$.

"Values are for $\mathrm{Cr}_{2} \mathrm{PO}_{4}$ (Ref. 16).

'By ellipsometry.

featureless. Semiquantitative analysis showed no measurable variations in composition of the two sides to within approximately $1 \mu \mathrm{m}$ depth. This is in contrast to the results reported for a related system of amorphous $\mathrm{Fe}-\mathrm{Ni}-\mathrm{Cr}-\mathrm{C}$, ${ }^{12,13}$ where a gradient of composition for chromium was found with higher chromium concentration on the dull side of the film.

The potentiomdynamic polarization measurements (Fig. 2) yielded different characteristics of current density in the region near the corrosion potential depending upon the surface morphology. The dull samples exhibited an active region while the shiny side passivated spontaneously. Since the current density curves for the polished dull and the shiny sides are identical, only the results for the shiny surface are reported. ${ }^{14}$
The current density curve (Fig. 2), exhibited the general chararacteristics as those reported by $\mathbb{K}$ awashima, Asami, and Hashimoto ${ }^{15}$ for $\mathrm{Ni}-9 \mathrm{Cr}-15 \mathrm{P}-5 \mathrm{~B}$ in $2 \mathrm{~N} \mathrm{H}_{2} \mathrm{SO}_{4}$ with spentaneous passivation and a comparable current density in the passive region.

According to Hashimoto and co-workers, ${ }^{7}$ amorphous alloys containing certain amounts of $\mathrm{Cr}$ and $\mathrm{P}$ passivate by forming a film consisting entirely of hydrated chromium oxylydroxide $\left[\mathrm{CrO}_{x}(\mathrm{OH})_{3 \ldots 2 x}{ }^{\circ} \mathrm{H}_{2} \mathrm{O}\right.$ ). Kawashima et al. ${ }^{15}$ reported that a Ni-10Cr-20P alloy in $1 \mathrm{~N} / \mathrm{HCl}$ showed preferential dissolution of nickel accompanied by increased surface concentrations of chromium and phosphorus yielding chromium oxyhydroxide and chromium phosphate films. Our resulis are consistent with the above and can be understood in terms of the dissolution of Ni from the surface, and with the film-forming properties of $\mathrm{Cr}$ and $\mathrm{P}$ in amorphous alloy systems. $7,15,16$

Near-normal reflectance measurements were made in situ at wavelengths of 400,532 , and $700 \mathrm{~nm}$ during anodic polarization from the corrosion potential up to $1.7 \mathrm{~V}$. Typical results are shown in Fig. 3. As current increases at about $1.0 \mathrm{~V}$ the reffectance exhibits an overall decay in intensity with fuctuations which become quite uniformly periodic in the region of constant current. The relative decrease in intensity is strongly dependent upon wavelength. The interferometric measurements of film thickness on a polished surface anodically swept to the point of the first reflectance maximum in 400-nm light indicated the presence of a surface film about $130 \mathrm{~nm}$ thick. The above results suggest that overall increase ir: absorption and the periodic fluctuations of the refiectance can be related to a film-forming process with the film thickness increasing with time and potential.

A simple model was deveioped which consists of a single dielectric thin film with a single reflection at each of the two

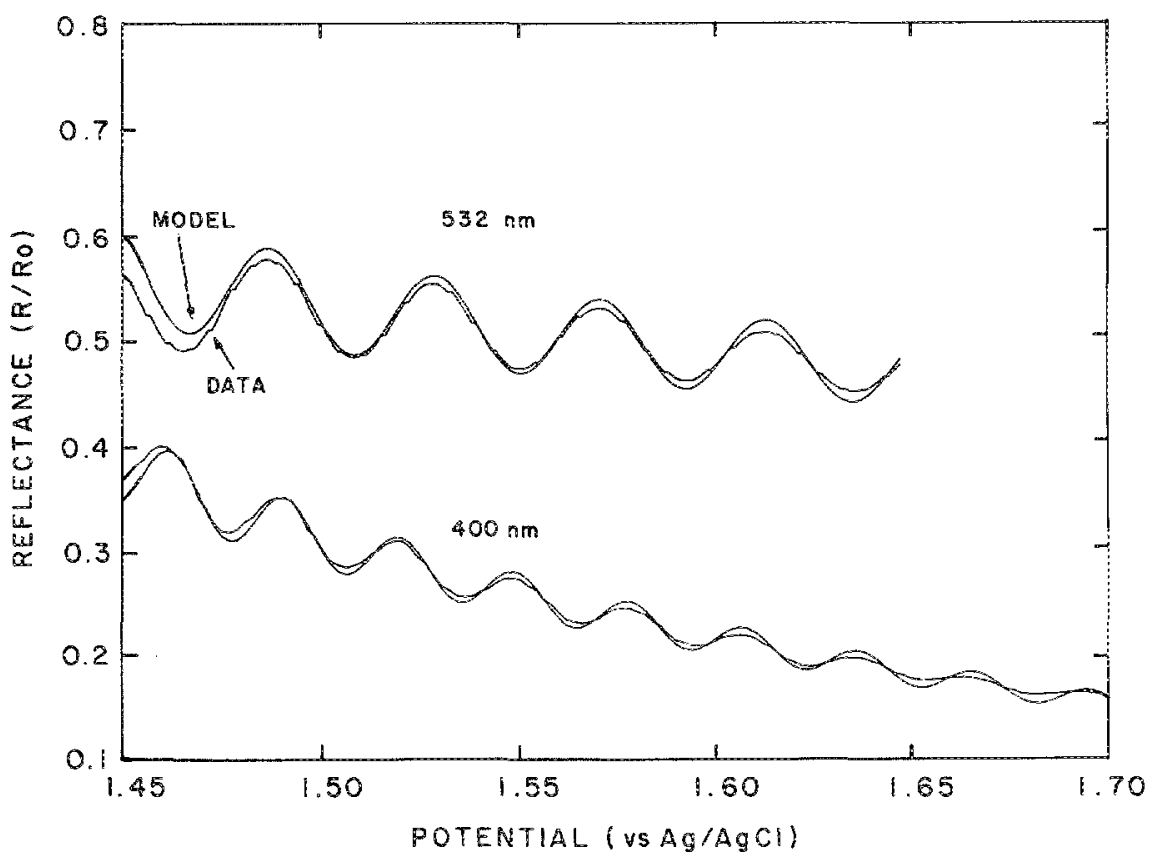

PIG. 4. Plot of normalized reffectance of the surface and the theoretical single-layer model for MPF65 ( $\mathrm{Ni}-14 \mathrm{Cr}-10 \mathrm{P}-0.5 \mathrm{C}$ ) in $1 \mathrm{~N} \mathrm{H}_{2} \mathrm{SO}_{4}$ at 400 and $500 \mathrm{~nm}$. 
interfaces: electrolyte/fim and film/metal. Using the data in Table 1 , the relative intensity, or reflectance, as a function of fim thickness $t_{2}$ can be expressed as follows:

$$
\begin{aligned}
I= & {\left[\exp \left(-2 \beta t_{1}\right)\right]\left[\sigma_{0}^{2}+\left(1-\sigma_{0}^{2}\right) \sigma_{1}^{2} \exp \left(-2 \alpha t_{2}\right)\right.} \\
& \left.+2 \sigma_{0} \sigma_{1}\left(1-\sigma_{0}^{2}\right) \exp \left(-\alpha t_{2}\right) \cos (\delta)\right]
\end{aligned}
$$

where $\sigma_{0}$ and $\sigma_{1}$ are the reffection coefficients at normal incidence of the top and lower interfaces (a function of their respective indices of refraction $n$ and absorption $k$ ), $\alpha$ is the film absorption coefficient equal to $4 \pi k_{0} \lambda$, and $\delta$ is the twobeam phase difference which is a function of the film thickness, its index of refraction, and the phase change of the reflection from each interface. The electrolyte was taken as an optical medium with an index of absorption $\beta$ and thickness $t_{1}$. For the index of refraction of the film we took $n=1.58$, the value for chromium phosphate reported in the transpassive region in a similar system $(\mathrm{Ni}-10 \mathrm{Cr}-10 \mathrm{P})$ by Kawashima ${ }^{7}$ in $1 N \mathrm{HCl}$. Values of $n$ and $k$ for the untreated polished surface are in general agreernent with the published values for nickel. ${ }^{17}$

For a comparison of the results calculated from the model and the experimental data, the potential was related to thickness by assuming the increase in thickness between successive reflectance maxima as $1 / 2$ a wavelength of the monitoring light. This comparison is shown in Fig. 4 for wavelengths of 400 and $532 \mathrm{~nm}$. At both wavelengths the overall exponential decay of reflectance shows good agreement with the predicted absorption by both the film and the electrolyte. At both 400 and 532 nm the film growth rate is approximately $7 \mathrm{~nm} / \mathrm{s}$ at a $1.67 \mathrm{mV} / \mathrm{s}$ sweep rate. ${ }^{18}$

We wish to acknowledge the very helpful suggestions and assistance of Dr. F. M. Hawkridge, Dr. D. D. Shillady, Dr. L. M. Vallarino, and J. Scrivener of the Virginia Commonwealth University Chemistry Department and Dr. A. S. Arrott from Simon Fraser University.

'H. Beck and H. J. Guntherodt, Eds., Glassy Metals II (Springer, Berlin, 1983).

${ }^{2} \mathrm{~K}$. Hashimoto, in Passivity of Metals and Semiconductors, edited by $\mathbf{M}$. Fremont (Elsevier, Amsterdam, 1983), p. 235.

${ }^{7}$ R. B. Diegle, N. R. Sorensen, T. Tsuru, and R. M. Latanision, in Treatise of Materials and Technology, edited by J. C. Scully (Academic, New York, 1983), p. 59.

${ }^{4}$ V. A. Niculescu, J. Hammerberg, and B. W. Sloope, Bull. Am. Phys. Soc. 30, 521 (1985).

${ }^{5} \mathrm{~V}$. A. Niculescu and J. Hammerberg, J. Electrockem. Soc. 123, 3, (1985).

${ }^{\circ} \mathrm{K}$. Hashimoto, Suppl. Sci. Rep. Res. Inst. (Tohok a Univ.), A-28 (1980).

${ }^{7}$ A. Kawashima, K. Asami, and K. Hashimoto, Corros. Sci. 24, 807 (1984).

Allied Corporation Metglas Products Department, 6 Eastmans Road, Parsippany, NJ 07054.

${ }^{4}$ D. B. Hagan, V.A. Niculescu, and J. Spivey, Rev. Sci. Instrum. 58, 468 (1987); 56, 2339 (1987); J. Electrochem. Soc. 123, C375 (1985).

${ }^{10}$ C. H. Pyun and S. M. Park, Anal. Chem. 58, 251 (1986).

"D. E. Reed and F. M. Hawkridge, Anal. Chem. 59, 2334 (1987).

"I. Nagy, T. Tarnoczi, M. Hosso, and F. Pavlayak, Proceedings of the Symposium on Rapidly Quenched Metals (1983), p. 223.

13 . Farkas, L. Kiss, A. Lovlas, P. Kovacs, and E. Geczi, Proceedings of the Symposium of Rapidly Quenched Metals (1983), p. 367.

${ }^{4}$ D. B. Hagan, Thesis, Virginia Commonwealth University, Richmond, VA, 1988

${ }^{15}$ A. Kawastima, K. Asami, and K. Hashimoto, J. Non-Cryst. Solids 70, 69 (1985).

'Masumoto and K. Hashimoto, Ann. Rev. Mater. Sci. C8, 894 (1978).

"12. W. Ditchburn, Light, 3rd ed. (Academic, New York, 1976), p. 261.

${ }^{18 D}$ D. B. Hagan, V. A. Niculescu, and B. W. Sloope, Mater. Res. Bull. 23, $1009(1988)$.

\title{
Preparation and characterization of the filled tetrahedral semiconductor LiZnP film on quartz
}

\author{
K. Kuriyama, T. Katoh, and S. Tsujl \\ College of Engineering and Research Center of Ion Beam Technology, Hosei University, Koganei, \\ Tokyo 184, Japan
}

(Received 30 March 1989; accepted for publication 12 June 1989)

A cirect wide-gap semiconductor LiZnP has been prepared by rapid evaporation onto a quartz substrate. Various characterization techniques such as $\mathrm{x}$-ray analysis, Rutherford backscattering analysis, and scanning electron microscopy were used to evaluate the quality of the films. Single-phase films were obtained by annealing during 40 min at substrate temperatures ranging from 400 to $440^{\circ} \mathrm{C}$. The grains in the films were oriented preferentially to the $\langle 111\rangle$ direction with increasing substrate temperature. The optical transmission of the $\mathrm{LiZnP}$ films was observed to the short wavelength beyond an absorption edge $(\sim 600 \mathrm{~nm})$ of bulk materials. This suggests the existence of the imperfection such as accumulated impurities at grain boundaries.

Recently, Wood, Zunger, and de Groot ${ }^{1}$ have discussed the susceptibility of zinc-blende semiconductors to bandstructure modification by the insertion of small atoms at their tetrahedral interstitial sites. Their electronic structure calculation has predicted that LiZn? [viewed as a zincblende-like $(\mathrm{ZnP})$ - lattice partially filled with He-like $\mathrm{Li}^{+}$ interstitials $]$ is a novel type of direct-gap semiconductor, not encountered in any cubic III-V material. Among cubic III- 